\title{
Arrhythmogenic Right Ventricular Dysplasia
}

National Cancer Institute

\section{Source}

National Cancer Institute. Arrhythmogenic Right Ventricular Dysplasia. NCI Thesaurus. Code C84571.

A rare genetic disorder characterized by cardiomyopathy affecting the right ventricle. The heart tissue is replaced by fibrous and adipose tissues. It is characterized by ventricular arrhythmia and right ventricular dysfunction. It is a cause of sudden death. 